\title{
Estudo dos resíduos sólidos domésticos da terra indígena Rio das Cobras no município de Nova Laranjeiras, PR
}

\author{
Study of domestic solid waste of Rio das Cobras indigenous land in the \\ municipality of Nova Laranjeiras, PR
Étude des déchets solides domestiques des terres indigènes de Rio das Cobras dans la municipalité de Nova Laranjeiras, PR
Estudio de los residuos sólidos domésticos de la tierra indígena Rio das Cobras en el municipio de Nova Laranjeiras, PR

\author{
Ilda Cornélio ${ }^{1}$ \\ Gabriela Silva Moura ${ }^{1}$ \\ Janete Stoffel ${ }^{1}$ \\ Betina Muelbert ${ }^{1}$
}

\begin{abstract}
Recebido em 29/08/2017 revisado e aprovado em 26/04/2018; aceito em 05/05/2018
DOI:http://dx.doi.org/10.20435/inter.v0i0.1698
\end{abstract}

\begin{abstract}
Resumo: O trabalho teve por objetivo diagnosticar e quantificar a geração de resíduos sólidos domésticos (RSD) na terra indígena Rio das Cobras, Nova Laranjeiras, PR. Foi obtida uma média de 0,09 kg.habitante-1. dia-1. Embora a produção de RSD seja pequena, é relevante destacar a importância de políticas públicas e ações de educação ambiental que possibilitem minimizar os impactos dos resíduos no meio ambiente e o bem-estar físico e cultural dos povos indígenas.
\end{abstract}

Palavras-chave: comunidade indígena; meio ambiente; reciclagem; Kaingang.

Abstract: The objective of this study was to diagnose and quantify the generation of domestic solid waste (RSD) in the Rio das Cobras indigenous land, Nova Laranjeiras, PR. An average of 0.09 kg.habitant-1day-1 was obtained. Although RSD production is small, it is important to highlight the importance of public policies and environmental education actions that minimize the impacts of waste on the environment and the physical and cultural well-being of indigenous peoples.

Keywords: indigenous community; environment; recycling; Kaingang.

Résumé: L'objectif de cette étude était de diagnostiquer et quantifier la production de déchets solides domestiques (RSD) dans les terres indigènes de Rio das Cobras, Nova Laranjeiras, PR. Une moyenne de 0,09 kg.habitant-1 jour-1 a été obtenue. Bien que la production de RSD soit faible, il est important de souligner l'importance des politiques publiques et des actions d'éducation environnementale qui minimisent les impacts des déchets sur l'environnement et le bien-être physique et culturel des peuples autochtones.

Mots-clés: communauté indigene; environnement; recyclage; Kaingang.

Resumen: El trabajo tuvo por objetivo diagnosticar y cuantificar la generación de residuos sólidos domésticos (RSD) en la tierra indígena Rio das Cobras, Nova Laranjeiras-PR. Se obtuvo una media de 0,09 kg.habitante1dia-1. Aunque la producción de RSD es pequeña, es importante destacar la importancia de políticas públicas y acciones de educación ambiental que posibiliten minimizar los impactos de los residuos en el medio ambiente y el bienestar físico y cultural de los pueblos indígenas.

Palabras clave: comunidad indígena; medio ambiente; reciclaje; Kaingang.

\section{INTRODUÇÃO}

Nos últimos anos, tem-se verificado o aumento considerável na produção de lixo no mundo. Este tema tem ganhado destaque na atualidade, não só pela crescente quantidade de lixo produzido, mas também pelos impactos negativos sobre a população e o meio ambiente.

\footnotetext{
${ }^{1}$ Universidade Fronteira do Sul (UFSS), Laranjeira do Sul, Paraná, Brasil.
} 
Após a Revolução Industrial, as fábricas passaram a produzir bens de consumo em larga escala e introduziram novas embalagens no mercado, aumentando consideravelmente o volume e diversidade de resíduos gerados nos centros urbanos (PEIXOTO; CAMPOS; ALMEIDA, 2005), consequentemente intensificando os impactos ambientais.

Ao mesmo tempo, a concentração da população nas grandes cidades se elevou e a problemática da geração e descarte de lixo teve um grande impulso. Em consequência, os problemas sociais e ambientais tenderam a se agravar. À medida que se instaurou um novo padrão de produção com a industrialização, os recursos naturais iniciaram seu processo de esgotamento, e o consumismo que deveria suprir as necessidades dos seres humanos tende, apenas, a alimentar cada vez mais a indústria.

Segundo Marques (2005, p. 8):

A Revolução Industrial trouxe produção de bens em massa e, consequentemente, consumo nas mesmas proporções. As cidades começaram a crescer desordenadamente, acumulandose construções e pessoas nas circunvizinhanças das fábricas [...] produtos em massa, consumo em massa, problemas em massa.

No final do século XIX, a questão ambiental emergiu após a Segunda Guerra Mundial, promovendo importantes mudanças na visão do mundo. Com isso, a preocupação com a escassez e o esgotamento dos recursos naturais passa a ser foco central do discurso ecológico. Assim, o movimento ambientalista aponta os insustentáveis padrões de produção e consumo como um dos temas mais significativos da situação atual de crise ambiental. "Esta mudança de rumo aponta para a consideração do longo prazo e dos direitos das gerações futuras, contrariando o imediatismo ditado pelo sistema de produção" (PORTILHO, 2003).

No cenário atual, as mudanças que o desenvolvimento econômico e a globalização ocasionam no modo de vida das pessoas, caracterizada pela produção e consumo sempre crescentes, colocam em perigo as condições socioeconômicas, ambientais e culturais de muitas sociedades mundiais. O rápido aumento do volume de resíduos é um aspecto das crises ambientais, acompanhando o desenvolvimento global recente.

Segundo Aidis (2006), a geração de resíduos não é impulsionada apenas pelos fatores econômicos e comportamentais, mas também pela influência do aumento populacional e sua concentração nos centros urbanos. De acordo com Bhada-Tata e Hoornweg (2012), vários são os aspectos que influenciam na composição e taxa de geração dos resíduos, dentre elas, a condição socioeconômica da população, ou seja, quanto maior a renda da população e maior porcentagem urbana da população, maior é a quantidade de resíduos sólidos produzidos, consequentemente maior dificuldade para se encontrar um destino correto e ambientalmente adequado para eles.

O aumento na produção de lixo não tem sido somente um problema dos centros urbanos, mas pode ser percebido também em comunidades tradicionais, como os povos indígenas. Nesse contexto, é significante destacar que, na sociedade tradicional indígena, não existia lixo, pois os resíduos encontrados nesses ambientes eram facilmente destruídos ou decompostos pela natureza. As comunidades tradicionais indígenas criaram uma relação harmoniosa com a natureza, aliado ao vasto conhecimento e maneira diferente de usá-la e manejá-la, eles utilizam os recursos que a natureza os oferece de forma sustentável, pois a usam para a sua subsistência.

Entretanto as mudanças de hábitos têm propiciado, cada vez mais, um distanciamento da relação homem-natureza, inclusive em aldeias indígenas. Um dos principais fatores da aculturação indígena é a forte presença do não indígena. Exemplo disso ocorre na Terra Indígena Rio 
das Cobras, que se localiza próxima a uma rodovia Federal e à cidade de Nova Laranjeiras, PR. É perceptível a influência e hábitos não indígenas na população de etnia Kaingang que lá habita. Conforme ressalta Gonçalves (2006), a integração com os não indígenas, impulsiona o índio ao afastamento de seus hábitos, buscando incorporar cada vez mais o modo de vida moderno dos não indígenas.

Santos (2006, p. 44) aponta que "cultura é uma dimensão do processo social, da vida de uma sociedade". Sob esse ponto de vista, a cultura pode ser definida como costumes e valores de uma sociedade que está sujeita à transformação de acordo com o momento histórico.

Nesse contexto, é notório influências não indígenas incorporadas pela comunidade Kaingang da terra indígena Rio das Cobras, como a mudança de hábitos alimentares e de consumo. Esses aspectos fazem com que haja uma relação de dependência aos alimentos e produtos adquiridos nas cidades, aumentando assim o volume de resíduos. Dessa forma, a temática lixo na terra indígena Rio das Cobras é cada vez mais preocupante, pois, na maioria das vezes, resíduos são descartados no ambiente ou queimados, sem que haja um local apropriado para processamento e coleta deles. Além disso, o lixo não é coletado regularmente, e muitas comunidades indígenas desconhecem quando esta é realizada.

Por outro lado, coleta seletiva é um instrumento de gestão ambiental e deve ser usado para fins de reciclagem (GONÇALVES, 2003). Para o sucesso dessa implementação, faz-se necessário o envolvimento da comunidade, por meio de um programa de comunicação e educação ambiental, com adequada logística de coleta e sistema de escoamento dos materiais. A coleta seletiva deve ser planejada considerando esses três elos, sendo que o planejamento deve ser feito "de trás para frente", primeiro definindo a destinação a ser dada aos materiais, depois escolhendo a logística a ser adotada para a coleta e, só então, elaborando o programa de educação ambiental, que deve ser constante, e não apenas uma campanha.

Nesse contexto, o presente estudo teve como objetivo diagnosticar e quantificar a geração de resíduos sólidos domésticos (RSD) na terra indígena Rio das Cobras, no município de Nova Laranjeiras, Paraná, identificando o destino que Ihes é dado, além de buscar compreender a percepção indígena sobre lixo e meio ambiente.

\section{METODOLOGIA}

O presente trabalho foi realizado na Terra Indígena Rio das Cobras, no município de Nova Laranjeiras, Paraná, durante o ano de 2016. O contato com os participantes da pesquisa foi feito na língua Kaingang e traduzido para o português pela autora, que é indígena e residente na comunidade. O estudo envolveu famílias localizadas nas comunidades Sede, Vila Nova e Encruzilhada. O trabalho de campo foi desenvolvido em três fases: (1) entrevista com comunidade; (2) coleta e análise dos RSD nas residências; e (3) entrevista com alunos e professores.

Na primeira fase, foram aplicados questionários a quatro famílias de cada comunidade (totalizando 12 famílias) para buscar compreender a percepção delas sobre o lixo. Foram abordadas questões sobre lixo, separação, coleta seletiva e destino final dos resíduos sólidos, entre outros. Posteriormente, para a coleta e análise dos resíduos sólidos domésticos (fase 2) foram realizadas visitas a essas mesmas 12 famílias indígenas, nos períodos, maio e outubro de 2016.

As coletas foram realizadas a cada dois dias, durante 3 semanas, com 12 coletas/aldeia em cada um dos meses. Foram entregues às famílias sacos plásticos de 50 litros, sendo orientadas a utilizar o saco plástico preto para resíduo sólido orgânico, verde para resíduo sólido reciclável e 
azul para resíduo sólido não reciclável. Foram utilizados equipamentos para a manipulação dos resíduos como, luvas e balança convencional automática com capacidade máxima para $40 \mathrm{~kg}$. 0 peso de cada categoria de resíduos foi anotado em planilhas do Programa Libre OficceCalc para análise quantitativa e descritiva dos dados, no qual foi calculado a produção total de RSD em cada período e a produção em kg.habitante-1.dia-1, considerando a média de 4 habitantes por família.

Na terceira fase, foram realizadas entrevistas com aplicação de questões semiestruturadas para cinco estudantes do ensino fundamental e ensino médio, e cinco professores, sendo três com atuação na escola da aldeia Sede, um com atuação na escola pertencente à aldeia Vila Nova escola, e outro com atuação na aldeia Encruzilhada. Nessa etapa, foram abordadas questões sobre o meio ambiente, lixo e sala de aula. Foram levantadas questões a respeito da discussão da temática em sala de aula, ações para diminuir a produção de resíduos sólidos nas aldeias, se existem materiais bibliográficos sobre meio ambiente e resíduos sólidos domésticos na instituição de ensino e como estes são utilizados em sala de aula. Também foram questionados sobre o que seria preciso fazer para reduzir a quantidade de lixo produzido nas aldeias.

\section{RESULTADOS E DISCUSSÃO}

Os resultados da pesquisa mostraram que no período de maio, quando foram realizadas nove coletas nas três aldeias, referente a uma população de 72 habitantes, obteve-se produção total de resíduos sólidos domiciliares de $72,24 \mathrm{~kg}$, o que corresponde a 0,1 kg. habitante-1.dia-1. Nas coletas realizadas no mês outubro, foi obtida produção total de $51,68 \mathrm{~kg}$, obtendo-se uma geração per capita de aproximadamente 0,08 kg.habitante-1.dia-1. Assim, podemos inferir que a geração de resíduos sólidos domiciliares foram baixas se considerarmos que a produção média no estado do Paraná é de 0,94 kg. habitante-1.dia-1 (ABRELPE, 2014). Uma das possíveis explicações para este relativamente pequeno valor se deve ao fato de algumas famílias terem queimado o lixo que seria quantificado. Segundo dados do IPEA (2012), cada pessoa pode gerar diariamente de 0,5 a 1,0 kg de lixo por dia, o que significa uma produção de 100 a 200 mil toneladas de lixo por dia em média no Brasil.

Partindo desse contexto, foi possível evidenciar que 91,5\% dos entrevistados disseram que o lixo produzido em suas residências é queimado, e 8,5\% disseram que o lixo é jogado a céu aberto. A seguir serão transcritos alguns relatos das famílias entrevistas:

Embalo e levo para longe de minha casa, uns 100 metros e aí queimo para não fazer fumaça para casa. Porque a fumaça produz um mau cheiro e eu não gosto. (F1E) .

Queimado, mas tem alguns que não queimam, como fraldas descartáveis, vidros, ferro. $(F 2 V N)$.

Amontoo e queimo todas as sextas-feiras. Mas alguns vizinhos não gostam que eu queimo, porque acham o cheiro forte e ruim. (F3S).

Jogo no mato. Porque eu não gosto do mau cheiro de fumaça quando queimavam o lixo. Seria bom lugar próprio longe das nossas casas aqui na comunidade se construísse um buraco ou valeta para nós jogar o lixo, nós levava lá. (F4S).

É importante ressaltar que a queima é uma prática comum entre os povos indígenas, que utilizam para diversas finalidades. Segundo Leonel (2000), o fogo é um sistema primitivo, usado pelos povos indígenas, como conjunto de técnicas de manejo no trato da vegetação com 
o cuidado a ser dedicado aos animais, ou seja, a atração da caça e a garantia de alimentos e de outras plantas úteis. Segundo Hecht (2003); Mistry et al. (2005) e Schwartzman et al. (2013), o uso do fogo é uma pratica cooperativa, usada na agricultura e pecuária, na caça e coleta a pesca, para estimular o crescimento e a abundância da vegetação, desmate da vegetação, proteção do habitat, o uso doméstico e o uso medicinal/curandeiro e espiritual.

Quanto aos resultados, para cada categoria de resíduos foi obtido um total de 15,99 kg; 34,35 kg; e 21,88 kg de resíduos orgânicos, materiais recicláveis e materiais não recicláveis, respectivamente, no mês de maio. Resultados semelhantes foram obtidos para as coletas realizadas no mês de outubro, quando a produção de RSD foi de 14,16 kg; 22, 11 kg; e 15,39 kg para resíduos orgânicos, recicláveis e não recicláveis, respectivamente (Tabela 1).

Tabela 1 - Quantificação de resíduos domésticos (RSD) no período de maio e outubro nas aldeias Sede, Encruzilhada e Vila Nova da Terra Indígena Rio das Cobras, PR

\begin{tabular}{|c|c|c|c|c|}
\hline \multirow{3}{*}{ RSD } & \multicolumn{3}{|c|}{ Coleta mês de maio (kg) } & \multirow{3}{*}{ Total (kg) } \\
\hline & \multicolumn{3}{|c|}{ Aldeias } & \\
\hline & Sede & Encruzilhada & Vila Nova & \\
\hline Orgânico & 3,251 & 4,352 & 8,393 & 15,996 \\
\hline Reciclável & 15,333 & 9,406 & 9,619 & 34,358 \\
\hline \multirow[t]{3}{*}{ Não reciclável } & 3,356 & 11,869 & 6,663 & 21,888 \\
\hline & & & & 72,242 \\
\hline & \multicolumn{3}{|c|}{ Coleta mês de outubro (kg) } & \multirow{3}{*}{ Total (kg) } \\
\hline \multirow[t]{2}{*}{ RSD } & \multicolumn{3}{|c|}{ Aldeias } & \\
\hline & Sede & Encruzilhada & Vila Nova & \\
\hline Orgânico & 1,864 & 5,772 & 6,531 & 14,167 \\
\hline Reciclável & 4,764 & 10,737 & 6,611 & 22,112 \\
\hline \multirow[t]{2}{*}{ Não Reciclável } & 8,976 & 3,395 & 3,027 & 15,398 \\
\hline & & & & 51,687 \\
\hline
\end{tabular}

Fonte: Elaborado por Ilda Cornélio, 2016.

Nos dois períodos analisados, maior quantidade de resíduos foi evidenciada para a categoria dos materiais recicláveis. Esse resultado difere dos dados apresentados por Del Bianco (2014) que diz, da composição de cada lixo domiciliar brasileiro, 65\% são de natureza orgânica, 4\% de metal, $2,5 \%$ de papel e $3 \%$ de vidro e plástico, e o restante da porcentagem, cerca de $22,5 \%$, é composto por outros tipos de resíduos, dentre eles, de origem industrial, urbanos, de entulho, agrícolas, entre outros.

Os principais materiais recicláveis encontrados foram papelão, plástico, garrafas Pet e papel. Provavelmente, maior parte desses materiais adquiridos em mercados próximos. Salienta-se que, nesta pesquisa, 58\% dos entrevistados recebiam renda mensal fixa, cujo valor variava de $\mathrm{R} \$$ 80,00 a 700,00 reais, dependendo do número de integrantes na família, valor este proveniente do Programa Bolsa Família do Governo Federal. Apenas $8 \%$ das famílias disseram receber até dois salários mínimos ao mês.

Segundo Priprá (2015, p. 17),

Ferramentas, roupas, produtos domésticos e, principalmente, os alimentos industrializados começaram a fazer parte do dia a dia do povo indígena, que em princípio foram oferecidos como presente de amizade e ao longo desse contato pacífico serviu como instrumento de dominação e mudança cultural desse grupo social. 
Quanto aos resíduos orgânicos, foi possível evidenciar que eram constituídos principalmente de restos de alimentos, como cascas de frutas, verduras, pó de café e ervas. Embora a produção total de resíduos orgânicos em cada período de avaliação não tenha sido significativa, cabe destacar a importância de utilização desses resíduos no processo de compostagem, embora essa prática não tenha sido observada no local do estudo. A compostagem pode ser definida como o processo biológico de decomposição e de reciclagem da matéria orgânica contida em restos de origem animal ou vegetal, sendo o seu produto final utilizado como adubo orgânico no solo, melhorando suas características físicas, químicas e biológica, sem ocasionar risco ao meio ambiente (PRANDINI et al., 1995). Galbiati (2001) ressalta, ainda, que essa técnica pode contribuir em cerca de $50 \%$ para a redução da quantidade de lixo destinada aos aterros, gerando composto orgânico, ótimo condicionador de solos e fonte de nutrientes para as plantas.

Ainda são escassas pesquisas abordando o tema de resíduos e povos tradicionais, principalmente mais próximos as cidades. Izugbara e Umoh (2004) buscaram compreender as práticas de gestão de resíduos realizadas pelos indígenas e integrá-las em uma comunidade urbana. $\mathrm{E}$ destacaram que a separação, queima seletiva, enterramento, compostagem e conversão ajudam a proteger o meio ambiente natural e podem permitir recuperar danos ocasionados pela ação humana.

Em relação aos resíduos recicláveis, o total produzido foi de 56,47 kg em 18 dias de coleta. Considerando esse valor, o total obtido durante um ano chegaria a $1.145 \mathrm{~kg}$ para as doze famílias indígenas. Esse valor corresponde a aproximadamente 0,26 kg.habitante-1.dia-1.Vale destacar que a venda de material reciclado poderia ser uma alternativa de renda para as comunidades indígenas.

Nesse sentido, é fundamental o desenvolvimento de estratégias que possibilitem tanto a redução do lixo gerado pela comunidade, como a reutilização e a reciclagem de materiais que possam ser utilizados como fonte de renda.

Diante da pesquisa, observou-se também que não há um entendimento sobre o conceito de lixo entre os entrevistados. Foi constatado que a maioria das famílias não tinha compreensão sobre o que poderia ser reaproveitado, associando o lixo como algo que não tinha mais utilidade e que as famílias jogavam fora. O termo lixo pode ser subdividido em rejeitos e resíduos, sendo que estes últimos podem servir como matéria-prima para fabricação de outro produto. Conforme a Lei 12.305 de 2 de agosto de 2010, resíduos sólidos são aqueles itens cuja geração pode ser reduzida, ou que podem ser objeto de reutilização ou reciclagem, devendo sua destinação ser ambientalmente adequada. Por outro lado, rejeitos são os materiais que, depois de esgotadas todas as possibilidades de tratamento e recuperação por processos tecnológicos viáveis, não apresentam outra possibilidade senão a disposição final ambientalmente adequada em aterros controlados (BRASIL, 2012).

Na fase 3 deste trabalho, foram realizadas as entrevistas com os estudantes e professores da escola da Terra Indígena Rio das Cobras. Considerando a escola como um espaço de troca de saberes e construção do conhecimento, foi perguntando aos estudantes indígenas se, nesse ambiente, têm ocorrido discussões e/ou reflexões no sentido de minimizar a produção de resíduos sólidos domésticos para preservar o meio ambiente. Os alunos foram questionados sobre o que seria necessário fazer para diminuir a quantidade de lixo produzido nas aldeias e preservar o meio ambiente. Os estudantes responderam que: 
Os professores falam pouco sobre o Meio ambiente e o lixo na sala de aula, é por isso que muitos não sabem o que é isso", lixo a gente sabe o que é, mas não tem lugar aonde jogar esse lixo, é por isso que tem bastante perto das casas. (Estudante - Aldeia Sede).

Eu não sei muito sobre isso, porque os meus professores não falam muito sobre o Meio Ambiente e o lixo, as vezes a professora de geografia fala mais bem pouco. (Estudante Aldeia Sede).

Eu acho que poderia ser mais discutido em sala de aula esse problema, porque todos nós poderíamos aprender de como cuidar mais da nossa terra, dos rios e em redor das nossas casas, porque lá na minha casa também tem bastante lixo. E, às vezes, a minha mãe queima, mas as coisas grandes (eletrodomésticos) não queimam. (Estudante - Aldeia Vila Nova).

Falta informação mais clara para nos entender na escola, os professores e alguns que tem mais conhecimento poderiam dar palestras sobre o lixo. Porque até umas lideranças não conhecem isso, as lideranças também tem que começar a se preocupar com tanto lixo na aldeia, na minha aldeia o caminhão do lixo não passa é por isso que tem bastante lixo lá. (Estudante - Aldeia Encruzilhada).

Alguns dos nossos professores falam sobre o Meio Ambiente e o lixo na sala, mas, na maioria das vezes, não damos muita importância pra isso, mas na realidade essa pouca informação está causando um sério problema para a nossa comunidade, tem muito lixo em todas as aldeias. (Estudante - Aldeia Sede).

Na minha sala, tem uma professora que fala sobre o Meio Ambiente, mas ela não fala sobre o lixo. (Estudante - Aldeia Encruzilhada).

Só alguns professores falam sobre o Meio Ambiente, mas não entendo muita coisa, e sobre o lixo eles falam pouco, agora eu acho que é por isso que não sabemos o que fazer com muito lixo que tem nas nossas casas; na minha casa tem bastante lixo, tem até fogão velho e máquina de lavar roupa jogado perto de casa. (Estudante - Aldeia Sede).

Na minha sala ninguém fala sobre isso. (Estudante - Aldeia Vila Nova).

Eu queria que isso fosse mais falado em sala de aula, para todas as turmas, desde o primeiro ano do ensino fundamental assim, os professores estariam ensinando os alunos dos anos iniciais, e eles aprenderiam mais rápido. E a escola poderia fazer mais palestras e poderiam convidar a comunidade para participar. (Estudante - Aldeia Sede).

Silva (1995) sugere que uma das alternativas para amenizar a problemática dos resíduos sólidos seria iniciar trabalhos voltados para Educação Ambiental, como a implantação da coleta seletiva nas escolas para, depois, atingir os demais segmentos da sociedade.

Em relação aos cinco professores entrevistados, apenas dois disseram que o tema sobre lixo é discutido em sala de aula. Os demais apontaram que falar sobre essa temática não oferece resultados para diminuir o problema, e que, nesse caso, precisaria de apoio de políticas públicas em todos os níveis: federal, municipal e local. Desse modo, evidencia-se que nem todos os professores têm a percepção do quanto é fundamental que essa reflexão sobre a realidade em que se está inserido faça parte do cotidiano, principalmente no que diz respeito às questões ambientais, com destaque para o gerenciamento correto do lixo.

Nesse sentido, é preciso reforçar a importância da formação dos professores, no que tange à educação ambiental, a fim de fornecer embasamento multidisciplinar, e tornar presentes as problemáticas locais. Conforme destacam Persich e Silveira (2011), desenvolver ações pedagógicas relativas à educação ambiental propicia o desenvolvimento do senso crítico e participativo, levando a competências e habilidades que possibilitem a formação de cidadãos conscientes de 
seus direitos e deveres, direitos no sentido de usufruir da vida e ter condições de viver dignamente, podendo aproveitar os benefícios que a natureza proporciona, e dever no sentido de lutar para gozar desses benefícios.

\section{CONSIDERAÇÕES FINAIS}

Durante o decorrer da pesquisa, foi possível esclarecer várias dúvidas entre os participantes, em função dos procedimentos recomendados para a separação dos materiais orgânicos, recicláveis e não recicláveis. Constatou-se que maior volume de lixo ocorreu no período de maio. De acordo com os dados obtidos, a maioria do lixo produzido é do tipo orgânico e reciclável, e grande parte é jogado a céu aberto e/ou queimado, pois não há um local adequado de destinação.

Observou-se certa resistência inicial a mudanças de hábitos pelas comunidades, em relação ao processo de separação e, consequentemente, o encaminhamento dos materiais separados para a coleta do caminhão de lixo. Com o desenvolvimento do processo, notou-se uma possível melhora no entendimento do papel das aldeias em seu ambiente.

Por meio das análises dos dados, observou-se que os resíduos sólidos representam um problema na terra indígena estudada e que a pouca importância dada a esse tema com povos tradicionais é refletida pela escassez de estudos.

Nesse sentido, faz-se necessária a implantação e implementação de políticas públicas e ações de educação ambiental que possibilitem minimizar os problemas de descartes inadequados dos resíduos sólidos e realizar um direcionamento para a discussão sob a ótica do planejamento local.

É importante que as lideranças indígenas, poderes municipais e a iniciativa privada se unam para melhorar a qualidade de vida dos moradores das comunidades indígenas. Sugere-se aumento do número de coletas realizadas, não apenas nas escolas, mas em todas as aldeias, visto que há um grande intervalo de tempo entre tais coletas.

Faz-se necessário o acesso às políticas públicas em todos os níveis: federal, municipal e local, que tratem a redução do consumo como elemento estratégico para se atingir o desenvolvimento sustentável. Também se deve considerar que aspectos econômicos, sociais, ecológicos, culturais e éticos não podem ser tratados de forma dissociada.

\section{REFERÊNCIAS}

ASOCIACIÓN INTERAMERICANA DE INGENIERÍA SANITARIA Y AMBIENTAL. Directrices para la Gestion Integrada y Sostenible de Residuos Solidos Urbanos en America Latina y el Caribe. São Paulo: AIDIS, 2006. 118p. Disponível em: www.polis.org.br. Acesso em: 27 fev. 2017.

ASSOCIAÇÃO BRASILEIRA DE EMPRESAS DE LIMPEZA PÚBLICA E RESÍDUOS ESPECIAIS PANORAMA. São Paulo: ABRELPE, 2014. Disponível em: http://www.abrelpe.org.br/Panorama/panorama2014.pdf. Acesso em: 5 jan. 2016.

BHADA-TATA, P.; HOORNWEG, D. What a waste: a global review of solid waste management. Washington, 2012. 98 p. (Urban Development Series: knowledge papers, n. 15). Disponível em: http://wwwwds. worldbank.org/external/default/WDSContentServer/WDSP/IB/2012/07/25/000333037_20120725004 131/Rendered/PDF/681350WPOREVISOat0aOWaste20120Final.pdf. Acesso em: 9 maio 2016.

BRASIL. Lei n. 12.305, de 2 de agosto de 2010. Política nacional de resíduos sólidos 2. ed. Brasília: Câmara dos Deputados, Edições Câmara, 2012. 73 p. 
DEL BIANCO, T. S. Sustentabilidade e desenvolvimento regional: uma análise do potencial econômico dos resíduos sólidos urbanos no Oeste do Paraná - 1970-2020. Orientador: Ricardo Rippel. 2014. 157 f. Dissertação (Mestrado em Desenvolvimento Regional e Agronegócio) - Universidade Estadual do Oeste do Paraná (UNIOESTE), Toledo, PR, 2014.

GALBIATI, A. F. O gerenciamento integrado de resíduos sólidos e a reciclagem. Campo Grande: Limpeza Pública, 2001. Disponível em: http://www.limpezapublica.com.br/textos/97.pdf. Acesso em: jan. 2017

GONÇALVES, J. R. Relatório final de antropologia na área de duplicação da BR-386. Triunfo, Tabaí, Taquari, Fazenda Vila Nova, Bom Retiro do Sul e Estrela- R.S Aldeia Kaingang Terra Indígena Estrela. Tubarão: UNISUL, 2006.

GONÇALVES, P. A reciclagem integradora dos aspectos ambientais sociais e econômicos. Rio de Janeiro: DP\&A; FASE, 2003.

HECHT, S. B. Indigenous soil management and the creation of Amazonian dark earths: implications of Kayapo practices. In: LEHMANN, J.; KERN, D. C.; GLASER, B.; WOODS, W. I. (Ed.). Amazonian dark earths: origin, properties, management. Boston: Kluwer Academic Publishers, 2003. p. 355-72.

INSTITUTO DE PESQUISA ECONÔMICA (IPEA.) Diagnóstico de Educação Ambiental em Resíduos Sólidos. Brasília: IPEA, 2012. Disponível em: http://www.ipea.gov.br/portal/images/stories/PDFs/ relatoriopesquisa/121002_relatorio_educacao_ambiental.pdf. Acesso em: 19 abr 2017.

IZUGBARA, C.; UMOH, J. O. Indigenous waste management practices among the Ngwa of Southeastern Nigeria: some lessons and policy implications. The Environmentalist, v. 24, n. 2, p. 87-92, 2004.

LEONEL, M. O uso do fogo: o manejo indígena e a piromania da monocultura. Estudos Avançados, São Paulo, v. 14, n. 40, 2000.

MARQUES, José Roberto. Meio ambiente urbano. Rio de Janeiro: Ed. Forense Universitária, 2005.

MISTRY, J.; BERARDI, A.; ANDRADE, V.; KRAHÔ, T.; KRAHÔ, P.; LEONARDOS, O. Indigenous fire management in the cerrado of Brazil: the case of the Krahô of Tocantíns. Human Ecology, v. 33, n. 3, p. 365-86, 2005.

LEONEL, M. O uso do fogo: o manejo indígena e a piromania da monocultura. Estudos Avançados, São Paulo, v. 14, n. 40, 2000.

PEIXOTO, K.; CAMPOS, V. B. G.; ALMEIDA, M. A Coleta seletiva e a redução dos resíduos sólidos. [S.I.]: Instituto Militar de Engenharia, 2005.

PERSICH, J. C.; SILVEIRA, D. D. da. Gerenciamento de resíduos sólidos: a importância da educação ambiental no processo de implantação da coleta seletiva de lixo- o caso de ljuí/RS. Revista Eletrônica em Gestão, Educação e Tecnologia Ambiental, Santa Maria, RS, v. 4, n. 4, p. 416-26, 2011.

PORTILHO, F. Consumo verde, consumo sustentável e a ambientalização dos consumidores. Campinas: Unicamp/IFCH, 2003. Disponível em: www.uff.br/lacta/publicacoes/artigoFatimaPortilho.doc. Acesso em: 19 abr. 2018.

PRANDINI, F. L.; D'ALMEIDA, M. L. O.; JARDIM, N. S.; MANO, V. G. T.; WELLS, C.; CASTRO, A. P. de; SCHNEIDER, D. M. O gerenciamento integrado do lixo municipal. In: D’ALMEIDA, M. L. O.; VILHENA, A. (Coord.). Lixo municipal: manual de gerenciamento integrado. São Paulo: IPT/CEMPRE, 1995. [cap. 1]. 
PRIPRÁ, J. N.M. O tratamento do lixo e as implicações na aldeia palmeirinha da terra indígena Ibirama/ Laklãnõ, Santa Catarina. Monografia (Graduação) - Universidade Federal de Santa Catarina, SC, 2015. p. 23.

SANTOS, José Luiz dos. O que é cultura. São Paulo: Brasiliense, 2006. (Coleção Primeiros Passos).

SCHWARTZMAN, S., VILLAS BOAS, A., ONO, K. Y., FONSECA, M. G., DOBLAS, J., ZIMMERMAN, B., JUNQUEIRA, P., JEROZOLIMSKI, A., SALAZAR, M., JUNQUEIRA, R. P.; TORRES, M. The natural and social history of the indigenous lands and protected areas corridor of the Xingu River basin. Philosophical Transactions of the Royal Society B, [s.I.], v. 368, n. 161, 2013.

SILVA, J. A. A. Uma poética do lixo: repensando a sociedade e a educação a partir do lixo. 1995. Dissertação (Mestrado) - Universidade Federal Fluminense, Rio de Janeiro, 1995.

\section{Sobre os autores:}

Ilda Cornélio: Mestre em Agroecologia e Desenvolvimento Rural Sustentável, pela Universidade Federal da Fronteira Sul, Campus Laranjeiras do Sul, Paraná. Graduada em Serviço Social pela Universidade Estadual do Centro-Oeste. E-mail: ildysocial@gmail.com, Orcid: http://orcid.org/0000-0003-0479-8956

Gabriela Silva Moura: Bióloga e Pós-doutoranda do Programa de Pós-graduação Interdisciplinar em Agroecologia e Desenvolvimento Rural Sustentável (Mestrado), Univerisdade Federal da Fronteira Sul, Campus Laranjeiras do Sul, Paraná. E-mail: bismoura@hotmail.com, Orcid: http://orcid.org/0000-0003-0404-2331

Janete Stoffel: Graduada em Ciências Econômicas pela Universidade Regional do Noroeste do Estado do Rio Grande do Sul, UNIJUI e Professora Doutora do curso de Ciências Econômicas e do Programa de Pós-graduação Interdisciplinar em Agroecologia e Desenvolvimento Rural Sustentável (Mestrado) da Universidade Federal da Fronteira Sul (UFFS), Campus de Laranjeiras do Sul, PR. E-mail: janete.stoffel@uffs.edu.br, Orcid: http://orcid.org/0000-0003-0689-0414

Betina Muelbert: Engenheira Agronôma pela Universidade Federal de Viçosa. Professora Associada 1 da Universidade Federal da Fronteira Sul. Professora Doutora nos cursos de Engenharia de Aquicultura e do Programa de Pós-graduação Interdisciplinar em Agroecologia e Desenvolvimento Rural Sustentável (Mestrado) da Universidade Federal da Fronteira Sul (UFFS), Campus de Laranjeiras do Sul, PR. E-mail: betina.muelbert@uffs.edu.br, Orcid: http://orcid.org/0000-0001-6930-9231 